\title{
EXPERIENCIA, ABORTO Y MATERNIDAD EN LAS CATÓLICAS FEMINISTAS
}

Pablo Gudiño Bessone ${ }^{1}$

Instituto de Desarrollo Económico y Social

IDES - CONICET, Argentina

http://dx.doi.org/10.5209/rev_NOMA.2012.v34.n2.40737

Resumen.- La oposición de la Iglesia Católica a las demandas feministas por la despenalización del aborto, permite visualizar las disputas y tensiones que se van dando en el espacio del catolicismo respecto a la resignificación de los valores tradicionales que representan a la mujer. En sus demandas por los derechos de género, la Red Latinoamericana de Católicas por el Derecho a Decidir -una corriente autónoma de mujeres católicas que a su vez se reivindican como feministas- conciben el acceso a los métodos anticonceptivos seguros y a la despenalización del aborto como un ejemplo de la libertad de conciencia. En este ensayo, abordamos los argumentos y postulados normativos de la jerarquía eclesiástica respecto al aborto, la sexualidad y la reproducción, al mismo tiempo que nos proponemos analizar la narrativa político-discursiva de éste colectivo de mujeres y sus argumentos a favor del derecho a decidir sobre el propio cuerpo.

Palabras clave.- Iglesia Católica, feministas, aborto, experiencia, maternidad.

Abstract.- The Catholic Church's opposition to feminist demands for the decriminalization of abortion, allows to visualize the disputes and tensions that are taking place within the field of Catholicism over the redefinition of traditional values that represent women. In their demands for the gender rights, the Latin-American Network of Catholics for a Free Choise -a current of catholic women whom also vindicate themselves as feminists- conceives access to safe contraception and the legalization of abortion as an example of freedom of conscience. In this essay we analyze the normative postulates of the ecclesiastic hierarchy with regard to the sexuality and the reproduction, at the same time as we propose to study the political-discursive narrative of this collective of women and their arguments in favour of the right to decide on the own body.

Keywords.- Catholic Church, feminists, abortion, experience, motherhood.

\section{Introducción}

Para Católicas por el Derecho a Decidir el posicionamiento de la jerarquía eclesiástica se caracteriza por imponer un estereotipo único de mujer en el que su rol sólo queda asignado al servicio de la familia y el don de la maternidad. Para las mismas, en lo que refiere al aborto, la Iglesia Católica fomenta la cuestión de la culpa en las mujeres sosteniendo que el reclamo por la disposición libre del cuerpo induce a una restricción arbitraria del derecho a la vida del "no nacido" en tanto sujeto acreedor de un estatus ontológico y jurídico que lo hace inviolable. Dicho estigma de culpabilización es interpretado por las

\footnotetext{
${ }^{1}$ Argentino. Licenciado en Ciencia Política por la Universidad Nacional de Villa María/ Córdoba (UNVM). Doctorando en Ciencias Sociales por el Instituto de Desarrollo Económico y Social/ Universidad Nacional de General Sarmiento (IDES/ UNGS). Becario del Consejo Nacional de Investigaciones Científicas y Técnicas (CONICET) y del Núcleo de Estudios sobre Memoria del IDES. Líneas principales de investigación: análisis del discurso, teoría política, género, catolicismo y memoria. Título de la investigación actual: "No matarás. La Iglesia Católica y la disputa por la vida en el marco de la memoria". E-mail: pablo_bessone7@hotmail.com
} 
católicas feministas como una restricción impuesta hacia sus derechos de ciudadanía y de género, donde los límites impuestos a la expresión de una fe libertaria las condena a la mera condición de seres a los que sólo se les reconoce su capacidad de reproducir y de ser madres. En este sentido, el aborto como instancia que empodera a las mujeres -dado que les concede la posibilidad de decidir, de reflexionar y de ubicarse en relación de igualdad respecto a los hombres- es planteado por parte de este colectivo de mujeres desde la resignificación de aquella diferencia a partir de la cual la jerarquía eclesiástica intenta subordinarlas; esto es, el uso político y discursivo de la maternidad.

El presente trabajo, aborda cómo el discurso de las católicas feministas -en tanto discurso que se presenta como radical respecto a los presupuestos de los órdenes eclesiásticos- opera en el marco de una resignificación política de los valores tradicionales del catolicismo. Al mismo tiempo que la Iglesia Católica limita la sexualidad de la mujer a su condición reproductora, es en nombre de la maternidad y de su resignificación simbólica -la capacidad de elegir ser o no ser madres- que el aborto es planteado por las católicas feministas como una cuestión de derechos humanos que contribuye a la ampliación de los derechos de ciudadanía y a la equidad de género. La Red Latinoamericana de Católicas por el Derecho a Decidir ejerce en el contexto de la región una fuerte disputa respecto al reconocimiento por la libre disposición del cuerpo de la mujer, el derecho a la salud sexual y reproductiva y el ejercicio voluntario de la maternidad. Mediante una tarea de reconstrucción de sus identidades como mujeres católicas, buscan esclarecer en la sociedad sobre la responsabilidad y la oportunidad de las mujeres a una maternidad escogida y deseada y el modo en que ésta, necesariamente, no se encuentra disociada del derecho al aborto.

\section{La Iglesia Católica y el conflicto por los postulados de la maternidad.}

Para Católicas por el Derecho a Decidir, los postulados que la jerarquía eclesiástica impone hacia las mujeres confinándolas a un lugar de subordinación en el que su rol social sólo queda asignado a la tarea de servir y de ser madres, es una clara evidencia de cómo las relaciones de género que operan al interior de la Iglesia Católica permanecen atravesadas por la existencia de relaciones de poder entre hombres y mujeres. A propósito de ello, para la teórica feminista Joan W. Scott, los modos de significación que circundan en el marco de las diferenciaciones de género adquieren, en su generalidad, la forma de oposiciones binarias. La efectividad de las construcciones normativas acerca del status que hombres y mujeres deben asumir tanto en la sociedad como al interior de las instituciones es dependiente del rechazo y de la negación hacia otras posibilidades alternativas de comprender las relaciones de género (Scott, 1993: 35). En este sentido, las tensiones que se dan en el campo del catolicismo en torno al reclamo que éste colectivo feminista despierta con relación a la necesidad de que las mujeres sean emancipadas de su relación de inferioridad respecto a los hombres, conlleva hacia un cuestionamiento de los patrones de significación masculina a partir de los cuales, tradicionalmente, en la Iglesia Católica se ha de concebir a las mujeres. 
A propósito, Scott sostiene que el género, entendido como categoría de análisis, nos permite abordar en qué medida las representaciones genéricas entre las cuales se encuentran las relaciones instituidas en el marco de la religión- funcionan como modos de asignación de jerarquía entre los sexos. ${ }^{2}$ En tanto relación de significación, la superioridad masculina no puede ser interpretada sino a partir de la subordinación y opresión hacia las mujeres. De tal modo, el análisis deconstructivo de la autora nos otorga la posibilidad de indagar cómo las demarcaciones de género son construidas y legitimadas desde las exclusiones mismas que suponen las asimetrías de poder. ${ }^{3}$ Si bien el género ha de ser considerado como una construcción política y cultural, de por sí que es inevitable no aludir a su carácter histórico, cultural y arbitrario.

Respecto a la negativa hacia el aborto, los postulados y argumentos desplegados por la Iglesia Católica no sólo deben ser abordados desde el plano religioso sino también desde la articulación que dicha institución hace con relación al accionar de otras instituciones profesionales de bioética católica y al protagonismo asumido en la esfera pública por el colectivo de militantes laicos pro-vida; esto es, la tríada que en torno a la conformación de un discurso político en defensa de la "vida" se establece entre los presupuestos religiosos, jurídicos y bioéticos. En este aspecto, es considerable el modo en que el activismo político de la jerarquía eclesiástica se caracteriza por un creciente secularismo estratégico ${ }^{4}$ que no sólo le permite manifestar su oposición al aborto desde sus postulados teológicos y doctrinarios, sino también desde la

\footnotetext{
${ }^{2}$ Por género, Joan $\mathrm{W}$. Scott entiende el sistema de relaciones que constituyen y representan cultural y políticamente la diferencia sexual: "De esto sigue luego que el género es la organización social de la diferencia sexual. Pero esto no significa que el género refleje o implemente diferencias físicas, naturales y fijas entre hombres y mujeres; mas bien el genero es el conocimiento que establece significados a las diferencias corporales" (Scott, 1999: 2)

${ }^{3}$ Por medio de la aplicación de la metodología de la deconstrucción de Jacques Derrida, Joan W. Scott analiza la forma en que operan las oposiciones binarias de género. Para ello, se dedica a desplazar e invertir su construcción histórica, cultural y arbitraria; restando espacio a la aceptación de las diferencias mismas como atributos de la naturaleza (Scott, 2008: 68). En este sentido, la metodología de la deconstrucción "[...] no se limita a ser una crítica, sobre todo una crítica teórica, sino que debe desplazar las estructuras institucionales y los modelos sociales" (Derrida, 1989: 11).

${ }^{4}$ La Iglesia Católica respalda sus argumentos en oposición al aborto y la anticoncepción en los fundamentos del Consorcio de Abogados y Médicos Católicos y los comités universitarios de bioética, como así también en el activismo militante de distintas entidades laicas pro-vida. Mediante el despliegue de un discurso jurídico, médico y cientificista, la Iglesia Católica intenta inscribir sus fundamentos en el protagonismo político y civil de estas entidades. En su disputa con los movimientos feministas que proclaman la libre disposición del cuerpo de la mujer, la Iglesia activa un discurso estratégico pro-vida que no implica, necesariamente, un discurso más abierto y plural, sino que conlleva el mismo nivel de dogmatismo que las convicciones religiosas. El sociólogo argentino Juan Marco Vaggione analiza bajo el término "secularismo estratégico" los distintos tipos de cambios y mutaciones en el discurso del catolicismo a fin de comprender las argumentaciones normativas con que la Iglesia Católica se opone al reconocimiento de los derechos sexuales y reproductivos. En este sentido, el autor considera que el uso de justificaciones seculares ha devenido el eje central de su accionar en la esfera pública acompañada por el activismo que asumen dichas entidades pro-vida. Ello supone analizar cómo el activismo político llevado a cabo por la Iglesia Católica se conduce a desplazar la dicotomía religioso/secular, intentando incorporar al marco de sus argumentos nuevos discursos que le permitan operar con eficacia dentro de los espacios que habilitan los sistemas democráticos (Vaggione, 2005: 152).
} 
inscripción del debate por el derecho a la vida del "no nacido" en el conjunto de los argumentos basados en el cientificismo médico y jurídico (Vaggione, 2005: 150):

De acuerdo con la encíclica Evangelium vitae (Juan Pablo II, 1995), reafirmamos nuestra convicción de que "el hombre está llamado a una plenitud de vida que va más allá de las dimensiones de su existencia terrena, ya que consiste en la participación de la vida misma de Dios [...] Este evangelio debe ser anunciado a todos los hombres y a todas las mujeres, para que puedan amar la vida de todo ser humano y fortalecer su conciencia sobre la necesidad de la defensa de la vida, también durante la experiencia terrena, desde la fecundación hasta la muerte natural. Analizando el debate internacional de estos últimos cinco años, reconocemos la gran actualidad de la encíclica, en la que la Iglesia presenta su posición de condena con respecto a una serie de atentados contra la vida humana, como son la anticoncepción, la esterilización, el aborto, la procreación artificial, la producción de embriones humanos, sujetos a manipulación o a destrucción, y la eutanasia. Hoy cada vez más exigen una vigilancia social y jurídica, puesto que se tiende a darles el carácter de derechos positivos. La característica peculiar de nuestro tiempo no consiste sólo en el asesinato del hombre inocente, pues que se ha perpetrado desde la antigüedad, sino, lo que es aún más grave, en la legalización, en determinadas circunstancias, de ese delito, como si fuera "un derecho" (Academia Pontificia Para la Vida, Comunicado de la VI Asamblea General, Santa Sede, 2000)

Para Católicas por el Derecho a Decidir, la oposición de la Iglesia Católica al aborto no se reduce al hecho de ejercer un disciplinamiento sobre la sexualidad y los cuerpos, sino también en la necesidad de imponer una estigmatización social sobre aquel conjunto de mujeres que optan por la interrupción de un embarazo; en otras palabras, en el fomento de la moralidad y la culpa. Para las católicas feministas, el dispositivo de culpabilización que opera desde la jerarquía eclesiástica en cuestiones que tienen que ver tanto con la práctica anticonceptiva como con el aborto no hace más que reforzar un estado de hostilidad hacia la mujer. Para las mismas, el hecho de ser madres no es concebido por las autoridades de la institución católica desde el placer ni desde la posibilidad misma de elegir. La consideración que la Iglesia Católica hace del "no nacido" como sujeto de derecho desde el momento mismo de la concepción, ubica a la mujer en el marco de una encrucijada en la que, además de disputar por su posición y rango subordinado en las relaciones de género, la enfrenta, también, a las facultades jurídicas y personales concedidas al "niño por nacer": "Ante un embarazo no deseado no se podrá pensar en un aborto, porque hasta un feto tiene, desde esta concepción, más derechos que la propia mujer" (Alanís, CDD-Córdoba, 2004: 4)

Para la Iglesia Católica el "no nacido" es considerado desde su concepción un nuevo ser, independiente, personal, que no pertenece al cuerpo biológico de la madre, ni se encuentra sujeto al arbitrio humano; es interpretado como un sujeto inalienable de derechos. "¿Y qué se puede pensar de cuantos se dicen "modernos" y de manera "perversa" quieran desconocer la condición de "ser humano completo y distinto" al recién concebido? Pues que necesitan de la

\footnotetext{
${ }^{5}$ De ahora en adelante con la sigla CDD hacemos alusión a Católicas por el Derecho a Decidir.
} 
mentira para poder justificar el aborto voluntario, que no es otra cosa sino "dar muerte a un ser humano inocente e indefenso" (Mons. Luis F. Gallardo Martín del Campo, obispo de Veracruz, México, 2009). El aborto es para la Iglesia Católica un acto homicida ya que implica la interrupción voluntaria de la vida de un ser indefenso e inocente. ${ }^{6}$ Pues el ingreso del "no nacido" al ámbito de lo jurídico hace que el cuerpo mismo de la mujer permanezca atravesado por un dispositivo jurídico que lo habita; es decir, por el efecto de personificación del "niño por nacer" cuestión mediante lo cual se pretende limitar los reclamos por el reconocimiento a la autodeterminación voluntaria del propio cuerpo:

[...] la mujer que aborta mata a su bebé. Desde el primer instante de la concepción está -científicamente- probado que el llamado feto es un bebé en desarrollo. La mujer que concibió es ya madre de esa personalizada criatura. Es vida humana engendrada por esa mujer. No es un pedazo de carne intrusa como puede ser un tumor. Es persona humana. Esta es la razón natural del no al aborto porque es un sí a esa criaturita de esa mujer que lo ha engendrado más allá del modo como se haya concebido. [...] La mujer que aborta intencionalmente comete un infanticidio. [...] La Iglesia sanciona con gravísima pena a los miembros que cometen tamaño delito. (Mons. Miguel E. Hesayne, obispo emérito de Viedma, Argentina, 2009)

Frente a los imperativos moralizantes que la jerarquía eclesiástica despliega sobre el cuerpo de la mujer, las católicas feministas consideran esencial encausar una lucha que tenga como fin derribar los criterios de imposición de una verdad única sobre la sexualidad y la reproducción. Para Católicas por el Derecho a Decidir, el evangelio resulta ser -desde la óptica de los imperativos eclesiásticos- un manual de normas que define de modo violento y arbitrario el estereotipo de lo que debe ser una mujer. El mito sagrado de la maternidad es considerado desde el sacrificio y el dolor, y no desde el goce, el placer y la libertad de elección. La permanente oposición de la Iglesia Católica al aborto, en tanto dicha práctica es comprendida como una cuestión delictiva y criminal, supone la intención de someter a las mujeres a una maternidad forzada, sin espacio para la libertad de elección sobre su propio cuerpo y su autonomía moral: "Observando también la práctica de Jesús con relación a las leyes de su tiempo, nos damos cuenta de su actitud liberadora, al defender la libertad humana frente a la ley [...] Esta actitud de Jesús denuncia la contradicción de la Iglesia en su práctica de elaboración de normas y leyes, que son formuladas en ausencia de las mujeres" (Puello Orozco, CDD-Brasil, 1998).

\footnotetext{
${ }^{6}$ Que la vida sea declarada personal a partir del acto de su concepción o a partir de cierto grado de desarrollo del embrión, no es otra cosa que su ingreso al régimen jurídico de persona. En Tercera Persona. Política de la vida y filosofía de lo impersonal, Roberto Esposito considera que la noción de persona es una referencia ineludible a los discursos éticos y políticos que reivindican el valor de la vida humana en cuanto tal. Respecto a las tensiones que se despiertan en torno al aborto entre las católicas feministas y las autoridades eclesiásticas, podemos decir que para las primeras la defensa que la jerarquía de la Iglesia hace del derecho a la vida del "no nacido" se sustenta en su menosprecio por el cuerpo. A diferencia de los supuestos eclesiásticos, Católicas por el Derecho a Decidir consideran que: "[...] la persona se constituye como tal en la medida en que tiene la capacidad -uso de razón- para poder decidir y en la medida en que decide se dignifica [...] Pensamos que afirmar el derecho a la vida desde la concepción lleva a la conclusión de que ningún aborto es no punible ni siquiera cuando peligra la vida de la madre" (Alanís, Juliá, CDD-Córdoba/ Argentina, 2004: 9)
} 
Para las católicas feministas, las connotaciones sociales que se construyen alrededor del aborto remiten a indagar acerca de los efectos de subordinación a los que las mujeres han quedado históricamente expuestas producto de la imposición de valores que son propios del orden patriarcal. ${ }^{7}$ Sostienen que el lugar adjudicado por la Iglesia Católica a las mujeres las ha condenado a ser consideradas exclusivamente como sujetos biológicos con la capacidad natural de reproducir, negándoles por ello su reconocimiento como sujetos de derecho dotados de la potestad de elegir y de deliberar sobre su propia maternidad. A diferencia de los hombres, las mismas consideran que la mujer ha permanecido condenada al sufrimiento y el dolor. Ni siquiera ante el acto abominable de la violación las mismas cuentan con la posibilidad de resarcir su dolor a través del reclamo por el reconocimiento de sus derechos. La negativa hacia las mujeres al control y elección de su capacidad reproductiva hace de la maternidad una herramienta de dependencia que somete a las mujeres a una condición meramente biológica y las subordina respecto a la superioridad masculina (Vasallo, 2005: 109). Para Católicas por el Derecho a Decidir, esa es la maniobra esencial que garantizó la continuidad del patriarcado; es lo que sustenta la asignación de las mujeres a su misión biológica de ser madres como la única admisible: "Lo que se percibe es el deseo profundo de una Iglesia masculina y misógina que siente el derecho a decidir lo que es mejor para las mujeres y para su vida, proponiendo un modelo de sumisión, sacrificio y sufrimiento" (Alanís, CDD-Córdobal Argentina, 2005: 3).

Para la Iglesia Católica, el impedimento de la maternidad es considerado como un crimen despiadado ya que contradice a la misión que Dios ha de conferirle por destino y obligación a la mujer: "Sea cual fuere el modo como se da la concepción -buscada o no, legítima, honesta o no, descontrolada, correctamente santa o no- toda maternidad es siempre sagrada" (Mons. Mario Maulión, Arzobispo de Paraná, Argentina, 2004). Para las católicas feministas, este tipo de imposición simbólica por parte de la jerarquía eclesiástica hacia las mujeres es resultado de una interpretación masculina de la religión que niega la capacidad ética y moral de las mismas para poder decidir sobre su cuerpo. Invocar a la maternidad como destino y parte del mandato divino es, asimismo, la imposición imaginaria y arbitraria de un Dios normativo y castigador, ajeno al reconocimiento del dolor y al padecimiento de las mujeres. Apoyadas en la tradición bíblica del Nuevo Testamento, Católicas por el Derecho a Decidir se oponen al imaginario de un Dios duro y exigente, pues consideran que "[...] la venida de Jesús marca un cambio en el sentido de que se privilegia el amor, incluso hasta se llega a decir ama y haz lo que quieras" (Alanís, CDD-Córdoba/ Argentina, 2005). Dicho supuesto, llevado a cabo por las mismas, debe ser interpretado como un intento por resignificar los valores tradicionales, normativos y excluyentes del catolicismo conservador.

\footnotetext{
${ }^{7}$ El patriarcado es un sistema sociopolítico que establece jerarquía sobre la base de la diferencia sexual. Éste se caracteriza por consagrar lo masculino como superior y paradigma de lo humano. El patriarcado tiende a suponer la dominación de las mujeres por parte de los hombres; implica relaciones de desigualdad genérica que intentan ser postuladas como estáticas y naturalizadas. Históricamente el término ha sido utilizado para designar un tipo de organización social en el que la autoridad la ejerce el varón. El poder en el patriarcado puede significar un origen divino, familiar, o fundarse en la existencia de voluntades arbitrarias y excluyentes (Fontanela, 2007: 256). En todos los casos el dominio de los varones sobre las mujeres se mantiene y es sobreentendido como una constante.
} 
Para las católicas feministas, la existencia de un Dios único, todopoderoso, masculino y castigador, es el reflejo de una de las primeras violencias simbólicas que la Iglesia Católica impone sobre el destino de las mujeres, su lugar en la sociedad y en la religión, sus cuerpos, su vidas, sus derechos. Para las mismas, ello es una muestra del modo en que los preceptos religiosos del catolicismo no han permanecido ajenos a las construcciones históricas y diferenciales del género ya que la voz silenciada de las mujeres da indicios de cómo las interpretaciones de la voluntad divina han quedado circunscriptas a la supremacía del poder patriarcal. Que la toma de decisiones en la Iglesia Católica haya quedado reservada a los hombres son considerado un ejemplo del modo en que la voluntad de Dios ha sido pensada constantemente desde la jerarquía y la dominación de género. Para las mismas, es a partir de la imbricación entre la sexualidad, la maternidad y la reproducción que la Iglesia Católica ha construido - históricamente- una maquinaria de control y dominio sobre el cuerpo de la mujer. Un cuerpo biologizado, naturalizado y sacralizado, a tal punto que se vuelve carga del sujeto que decide.

\section{Experiencia, aborto y los usos políticos de la maternidad.}

"Sin significado no hay experiencia: sin el proceso de significación no hay sentido" (Scott, 1993: 29). Mediante este supuesto, Joan W. Scott considera que la narrativa a partir de la cual los sujetos se identifican no permanece ajena a las relaciones de poder y de significación que los constituyen. A diferencia de la tradición histórica, la autora interpreta que la experiencia no debe ser concebida como el origen y causa de la explicación que los sujetos intentan dar sobre sí mismos sino más bien como aquello que debe intentar ser explicado historizado- a fin de comprender por qué los sujetos se constituyen en lo que "son". Para Scott, es en el marco de las representaciones políticas y sociales instituidas -en este caso las relaciones de género, de poder y el lugar que la mujer ocupa en el terreno del catolicismo- que la experiencia adquiere sentido. Pensar la experiencia de este modo permite darle historicidad a la vez que deconstruir las identidades que produce. La autora considera que la categoría de mujer ha sido un ideal regulatorio, normativo, un universal a partir del cual las mujeres mismas han sido interpretadas y ubicadas en la historia. ${ }^{8}$ Historizar

\footnotetext{
${ }^{8}$ Indagar cómo el concepto de mujer ha sido significado consiste precisamente en un desafío a las categorías de género históricamente establecidas. Joan W. Scott considera que la ortodoxia de la historia ha tomado el relato de la experiencia de las mujeres como una especie de evidencia incontrovertible, como el reflejo de una identidad basada en una sustancia, lo cual permitió dejar de lado el modo en que dicha identidad ha sido históricamente constituida. Para Scott, los estudios sobre la experiencia deben siempre poner en cuestión los supuestos originarios de la explicación histórica (Scott, 1992: 73). Al contrario de lo que ocurre en tratamientos de tipo histórico que dan por supuesta la identidad y experiencia de las mujeres, Scott considera que: "[...] un enfoque -de género- posestructuralista relativiza la identidad y la despoja de su base en una experiencia esencializada [...] Al problematizar -historizar- los conceptos de identidad y experiencia, las feministas que recurren al análisis posestructuralista han ofrecido interpretaciones dinámicas del género que hacen hincapié en la controversia, la contradicción ideológica y las complejidades de las relaciones cambiantes de poder. Por cierto, la obra consiste en la variabilidad histórica y en una especificidad contextual mayor para los significados mismos del género" (Scott, 1999: 83).
} 
la experiencia equivale a prestar atención a los procesos históricos y discursivos que se encargan de producir identidad en los sujetos. Equivale a luchar contra la existencia de categorías fijas, normativas y estáticas: "No son los individuos los que tienen la experiencia, sino los sujetos los que son constituidos por medio de la experiencia" (Scott, 2001: 49).

En el caso de Católicas por el Derecho a Decidir, podemos ver que la disputa que éste colectivo de mujeres emprende con relación a la jerarquía eclesiástica se centra en un replanteamiento de los términos a partir de los cuales la mujer ha sido históricamente significada en la Iglesia Católica. En sus reclamos políticos por ser escuchadas, por ser consideradas como sujetos de derecho con la capacidad de disponer en libertad de su cuerpo, las católicas feministas se manifiestan en contra de la culpa, del dolor y el sufrimiento que les confiere su experiencia como mujeres católicas. En consecuencia, prestar atención a sus argumentos discursivos nos permite observar el modo en que sus relatos se expresan desde la experiencia misma que históricamente las constituye:

La voz que tronó en el paraíso condenando a Eva a parir con dolor, se ha seguido escuchando a través de los siglos en las voces de los apóstoles, profetas, papas y obispos, quienes han responsabilizado al género femenino de la caída y del pecado. Así esta culpa milenaria ha recaído en todas las mujeres. En cada una de nosotras habita una pecadora y es imposible sustraerse a la malignidad de esta imagen [...] Nos educaron en creer de que gozar es cosa de putas y que sólo volviéndonos frígidas, sumisas y sufrientes alcanzaremos la redención a nuestros pecados. ¿Acaso el culto a la Virgen Dolorosa, no es la apoteosis masoquista de la opresión de las mujeres? (Alanís, CDD-Córdoba/ Argentina, 2005: 2)

En lo que confiere al reclamo por la legalización del aborto y el reconocimiento de los derechos sexuales y reproductivos, las católicas feministas asumen una estrategia político-discursiva en nombre de la experiencia que las caracteriza como mujeres católicas. Si bien cuestionan a la jerarquía eclesiástica por imponer a la maternidad como imperativo divino y destino forzado de la mujer, la potestad de concebir y de ser madres no deja de formar parte de su identidad e imaginario como grupo colectivo. En este sentido, el aborto entendido como una cuestión de justicia social y de equidad de género- no es considerado por las mismas ajeno a la maternidad (Alanís, CDD, 2009: 15). A propósito, para Scott, una de las estrategias centrales del feminismo se caracteriza en el hecho de partir de las definiciones oficiales e instituidas del género con la intensión de deconstruirlas y resignificarlas. Conforme a ello, podemos observar que los presupuestos políticos de las católicas feministas -la impronta por el reconocimiento de su dignidad humana como sujetos de derechos que incluyan la posibilidad de discernir sobre su sexualidad y reproducción en forma libre y voluntaria- se encuentran asociados a una resignificación política del sentido mismo de la maternidad. Estos es, una maternidad basada en la libertad, en el amor, en la conciencia, en la reflexión y no en el sufrimiento y el dolor que les confieren los presupuestos patriarcales que históricamente rigieron y, aún rigen, en la Iglesia Católica: 
Defender la salud y la vida de las mujeres, es una opción humana, ética, moral y es un compromiso como católicas. Pues la maternidad es un acto fundamentalmente amoroso, por ello nuestra apuesta es que los hijos e hijas que traigamos al mundo sean producto del deseo, del amor y del cariño [...] Si las mujeres somos las principales productoras de ese valor agregado, no se nos puede imponer, ni exigir renunciar a nuestra propia dignidad y autonomía [...] Como Católicas por el Derecho a Decidir no promovemos el aborto, ninguna persona lo promueve. Pero sí condenamos justa su despenalización (Mazo Cardona; Díaz; Lozano, CDD-Colombia, 2006: 29)

Para las católicas feministas, una de las formas de cuestionar los dogmas eclesiásticos consiste en la posibilidad de afianzar posturas éticas alternativas desde el mismo lenguaje teológico como la manera más eficaz de desarticular los fundamentalismos. En alusión a ello, Scott considera que hay momentos en que recurrir a categorías como la de maternidad adquiere eficacia y utilidad política, ya que permite operar en contextos particulares como lo es, en este caso, la esfera del catolicismo. Si bien el feminismo ha resistido -a lo largo de la historia- a la consolidación de las mujeres dentro de categorías homogéneas, estáticas y universalizantes; en cierto modo, la utilización política y estratégica de significantes como los de maternidad ha dado lugar a intervenciones creativas. En tanto el feminismo ha procurado señalar las desigualdades e inconsistencias permanentes en la sociedad entre hombres y mujeres, para Scott muchas veces las feministas "[...] han logrado llamar la atención a su causa al rechazar o reformular los usos generalmente aceptados del lenguaje, y con ello asombraron a las ortodoxias prevalecientes" (Scott, 2008: 16). En base a ello, podemos ver que mientras la jerarquía eclesiástica hace de la noción de maternidad un elemento clave para la conservación de valores tradicionales sobre sexualidad, el orden social y la familia, Católicas por el Derecho a Decidir resignifican dicha categoría desde una perspectiva feminista y católica, donde el imaginario mismo de la maternidad no permanece ajena a las demandas políticas por la despenalización del aborto:

Afirmamos desde nuestra identidad católica que toda persona es imagen y semejanza de Dios, dotada de inteligencia y libertad para decidir [...] La maternidad forzada deshumaniza a las mujeres mientras que la posibilidad de decidir, aunque esta decisión sea interrumpir un embarazo, humaniza a las mujeres, pues se pasa por un proceso en el que se evalúa, se reflexiona [...] Somos madres reales o potenciales porque la biología nos lo permite. La continuidad de un embarazo no tiene por qué ser la aceptación de una causalidad, sino la decisión amorosa de traer a una nueva persona al mundo. Por ello no es posible desvincular el aborto de la maternidad. (Vásquez, CDDCórdoba/ Argentina, 2005: 22)

Mediante las nociones de sexualidad placentera, maternidad voluntaria y disposición libre del cuerpo, las católicas feministas ejercen un cuestionamiento hacia los supuestos patriarcales que actúan en el seno de la Iglesia Católica. Son justamente estas disidencias las que las separan de la jerarquía eclesiástica y las acerca e inscribe en el movimiento feminista (Levín, 2010: 164). Los debates que las católicas feministas encarnan en torno a la reproducción y la maternidad, se constituyen en un punto central donde las 
posturas únicas y dogmáticas respecto a la sexualidad y el cuerpo quedan expuestas a constantes resignificaciones y disputas de sentido. La postura disidente que Católicas por el Derecho a Decidir asume respecto a la mirada institucional de la Iglesia Católica, refleja el modo en que dicho colectivo entrelaza su identidad religiosa con concepciones políticas y radicales del género. Por un lado, reafirman su pertenencia identitaria como mujeres católicas; por el otro, intentan mostrar el modo en que los consensos impuestos en el catolicismo respecto al imaginario social de la mujer ocultan un nivel de pluralización y disidencias a nivel de sus actores. Si bien ello permite evidenciar cómo el poder patriarcal y las relaciones de género en la Iglesia Católica son una construcción histórica y cultural, indica también el modo en que las católicas feministas pueden hacer uso de la noción de maternidad como una categoría política posible de ser reconstruida desde el mismo lenguaje teológico:

A partir de las enseñanzas de Jesús y de su movimiento, podemos afirmar nuevamente que el Evangelio no es un manual de normas. En cambio, sostenemos que sí es una fuente de valores que nos inspiran; que es un referente y un horizonte que nos invita a restituir nuestra dignidad humana como mujeres, a valorar el gran misterio de nuestra libertad, a reconocer que siempre tenemos un lugar sólo por ser quienes somos; que somos nuestros cuerpos llenos de poder y de deseos [...] Las mujeres que abortan son nuestras iguales; son personas con autoridad moral que nos revelan su sagrada libertad [...] La presencia y el poder de Dios no está sobre ellas; está en ellas, en sus vidas, en sus dilemas, en su sagrada decisión [...] Ellas siguen siendo invitadas al banquete y siempre tendrán un lugar en la mesa (Cruz Cárdenas, CDD-México, 2006: 23).

Lo que distingue a Católicas por el Derecho a Decidir es la articulación de su discurso religioso a los argumentos políticos por el reconocimiento de los derechos sexuales y reproductivos: esto es, el modo en que las mismas reivindican su identidad feminista en relación a la politización de su experiencia como mujeres católicas. En tanto la jerarquía eclesiástica intensifica su defensa de la vida y la familia a partir del despliegue de una postura normativa de la maternidad, podemos observar cómo las mismas -desde su concepción católica y feminista- conciben a la maternidad como a un acto voluntario, ligado al placer y a la libertad de elección sobre el propio cuerpo. A diferencia de quienes ejercen la representación de los valores más conservadores del catolicismo, las católicas feministas revisten a la categoría de maternidad de una significación distinta. Ésta deja de ser un principio rector tendiente a limitar la autonomía de la mujer sobre su cuerpo; a la vez que el aborto pasa a formar parte del ejercicio de una maternidad voluntaria, fundada en el amor, la reflexión, la libre conciencia y la coherencia cristiana de respetar el derecho a decidir. "Al ser María consultada -para ser madre de Dios- podemos comprender que la divinidad pregunta, consulta, solicita, convoca, invita. No arrebata, no impone, no invade, no violenta la voluntad [...] María representa, en su estampita, el libre albedrío, la obra por reflexión y elección" (Cruz Cárdenas, CDD-México, 2008: 2). 


\section{Consideraciones finales}

En el escenario actual del contexto latinoamericano la impronta por la despenalización del aborto y las demandas por el reconocimiento de los derechos sexuales y reproductivos adquieren relevancia como fenómeno social y político. En este sentido, el fenómeno de la disidencia religiosa se constituye en un espacio analítico crucial para la disputa sobre concepciones referidas al género. A raíz de los debates sobre lo que debe ser considerado como legítimo o no en materia de sexualidad y reproducción, la religión tiende a politizarse conduciendo así a una rediscusión sobre la estructuración de sus valores tradicionales. En este marco, la presencia y el protagonismo asumido por Católicas por el Derecho a Decidir ha dado lugar a un grado mayor de pluralismo y disidencia sobre la temática del aborto, asunto sobre el que la jerarquía eclesiástica pretende ejercer un predominio argumentativo y control unilateral. Sin embargo, el debilitamiento o no del poder hegemónico de la Iglesia Católica como institución no implica que su jerarquía y sus sectores laicos aliados sean menos poderosos e influyentes. Lo que sí estamos obligados a prestar atención es al modo en que la temática del aborto y la disputa por la vida, implica una redefinición del espacio del catolicismo a nivel de sus actores, estrategias y discursos.

\section{Bibliografía}

(2010) Academia Pontificia para la Vida: Comunicado de la VI Asamblea General, 11 al 14 de Febrero de 2000, Santa Sede. Disponible en: http://www.vatican.va/roman_curia/pontifical_academies/acdlife/documents/rc_ pa_acdlife_doc_20000214_final-doc_sp.htm- [Fecha de consulta 28 de Setiembre de 2010].

(2004) Alanís, Marte; Juliá, Silvia. (coords): Frente a la censura para hablar del aborto, nuestra boca es fundamental, Córdoba, Católicas por el Derecho a Decidir-Unifem Cono Sur.

(2004) Alanís, Marta: "Los fundamentalismos y su accionar en la región", en Alanís, Marta; Rodigou, M. (Eds.), Fundamentalismos. Las mujeres latinoamericanas se organizan, Córdoba, Católicas por el Derecho a DecidirCoordinación Latinoamericana Red Mujer y Hábitat. Pp. 4-8.

(2005) Alanís, Marta: La violencia hacia las mujeres viene de lejos, Córdoba, Católicas por el Derecho a Decidir-Córdoba.

(2009) Alanís, Marta: "Prólogo" en Carbajal, M. El aborto en debato. Aportes para una discusión pendiente, Buenos Aires, Paidós Tramas Sociales, pp. 1317.

(2009) Católicas por el Derecho a Decidir-Colombia: "La derecha católica en acción. Signos y silencios" en Revista Tejiendo Saberes, Boletín № 23, Bogotá: Católicas por el Derecho a Decidir-Colombia. Pp. 1-12. Disponible en: 
http://www.cddcolombia.org/page.php?mod=czoxNjoiY3pvek9pSndkVOIpT3c9P SI7\&st=1\&sec=29 [Fecha de consulta 29 de Abril de 2010].

(2006) Cruz Cárdenas, G: "Algunas reflexiones desde el evangelio sobre el aborto", en Gonzáles Henao, R.; Lozano, J.; Stegelmann, S.; Trillini, C. (Comps). Viejos Temas, nuevas miradas, Buenos Aires, Red Latinoamericana de Católicas por el Derecho a Decidir-Ford-Hivos, Pp. 17-27.

(2008) Cruz Cárdena, G: "María fue consultada para ser madre de Dios. Elegir es un derecho de todas", en AAVV, Libertad de conciencia. Hoja informativa dominical-Católicas por el Derecho a Decidir, $N^{\circ} 13$, México, Católicas por el Derecho a Decidir-México. Pp. 1-4.

(2009) Esposito, Roberto: Tercera persona. Política de la vida y filosofía de lo impersonal, Buenos Aires, Amorrortu.

(2007) Fontanela, María A: "Patriarcado", en Gamba, B. (coord.). Diccionario de estudios de género y feminismos, Buenos Aires, Biblos. Pp. 256-258.

(2006) Fernández, Alejandra., Tájer, Débora: "Los abortos y sus significaciones imaginarias: dispositivos políticos sobre los cuerpos de las mujeres", en Checa, S. (Comp). Realidades y coyunturas del aborto. Entre el derecho y la necesidad, Buenos Aires, Paidós. Pp. 33-47.

(2009) Gallardo Martín del Campo, L: Mensaje a toda la Iglesia Diocesana y a cuantos defiendan la vida de concebido aún no nacido en: http://www.cem.org.mx/index.php/noticias/diocesis-y-prelaturas/1226-mensajea-toda-la-iglesia-diocesana-y-a-cuantos-defienden-la-vida-del-concebido-aunno-nacido?format=pdf [Fecha de consulta 20 de Noviembre de 2010].

(2004) Gutiérrez, María: "Silencios y susurros: la cuestión de la anticoncepción y el aborto" en Cáceres C. (comp.). Ciudadanía Sexual en América latina. Abriendo el Debate, Lima, UPCH. Pp. 129-140.

(2009) Hesayne, Miguel: "El aborto es un crimen" en diario La Nación, Buenos Aires, 9 de Abril de 2009. Pp. 16.

(1987) Jelin, Elízabeth: "Ciudadanía e identidad: una reflexión final", en Jelin E. (comp.) Ciudadanía e Identidad: las mujeres en los movimientos sociales latinoamericanos, Ginebra, Instituto de Investigaciones de las Naciones Unidas para el Desarrollo Social/ Unsird. Pp. 311-354.

(2010) Levín, Silvia: Derechos al revés ¿ Salud sexual y salud reproductiva sin libertad?, Buenos Aires, Espacio Editorial.

(2004) Marcó, Guillermo: "No usar eufemismos: El aborto es un asesinato", en Agencia Informativa Católica Argentina (AICA), Buenos Aires, en: http://aica.org/aica/noticias/not_2004/SN/040120MA-01SN.htm [Fecha de consulta 12 de Mayo de 2010]. 
(2004) Maulión, Mario: "25 de marzo de 2004 anunciación del señor. Homilía para la celebración del día del Niño por Nacer", en Agencia Informativa Católica Argentina $(A / C A)$,

en http://aica.org/aica/documentos_files/Obispos_Argentinos/Maulion/2004/2004_0 3_25.htm [Fecha de consulta 12 de Junio de 2011].

(2006) Mazo Cardona, S.; Díaz, E.; Lozano, E: "La despenalización del aborto: Un asunto de justicia social" en Gonzáles Henao, R.; Lozano, J.; Stegelmann, S.; Trillini, C. (coords.), Viejos Temas, nuevas miradas, Buenos Aires, Red Latinoamericana de Católicas por el Derecho a Decidir/ Ford/ Hivos. Pp. 27-31.

(1996) Mejía, María Consuelo.; Martínez Mendoza, E. (coords.): Somos Iglesia, México, Católicas por el Derecho a Decidir-México.

(2006) Mejía, María Consuelo: "El aborto en la Iglesia Católica: entre la inhabilidad y el probabilismo" en Gonzáles Henao, R.; Lozano, J.; Stegelmann, S.; Trillini, C. (Comps) Viejos Temas, nuevas miradas, Buenos Aires, Red Latinoamericana de Católicas por el Derecho a Decidir-Ford-Hivos. Pp. 7-16.

(2007) Mujica, Jaris: Economía política del cuerpo. La reestructuración de los grupos conservadores y el biopoder, Lima, Promsex.

(1998) Puello Orozco, Yury: "Derechos Humanos en la Iglesia Católica desde la perspectiva de las mujeres" en Conciencia Latinoamericana, Vol. X, N², Julio/ Diciembre de 1998, Sao Pablo, CDD-Brasil. Pp 20-23.

(1993) Scott, Joan. W: "El género una categoría útil para el análisis histórico" en Cangiano, M. C.; Dubois, L. (Comps.), De mujer a género. Teoría, interpretación y práctica feminista en las Ciencias Sociales, Buenos Aires, Centro Editor de América Latina. Pp. 17-50.

(1994) Scott, Joan W: "Deconstruir igualdad-diferencia: usos de la teoría postestructuralista para el feminismo" en Feminaria, $\mathrm{N}^{\circ} 13$, Buenos Aires. Pp. 1-8.

(1996) Scott, Joan W: Only paradoxes to offer. French feminist and the rigths of man, Harvard University Press, Cambridge.

(1999) Scott, Joan W: "Historia de las mujeres" en Burke, P. (comp.), Formas de hacer historia. Madrid, Alianza. Pp. 59-88.

(2008) Scott, Joan W: Género e historia, Buenos Aires, Fondo de Cultura Económica.

(2005) Vaggione, Juan M: "Los roles políticos de la religión. Género y sexualidad más allá del secularismo" en Vasallo, M. (Comp) En nombre de la vida, Córdoba, Católicas por el Derecho a Decidir-Córdoba. Pp. 137-169. 
(2002) Vasallo, Marta: “¿Vida? ¿Cuál vida?" en AAVV. El Opus Dei y la restauración católica, Buenos Aires, Le Monde Diplomatique-Edición Cono Sur. Pp. 85-90.

(2005) Vasallo, Marta: "En nombre de la vida" en Vasallo, M. (comp.) En nombre de la vida, Córdoba, Católicas por el Derecho a Decidir-Córdoba, 2005. Pp. 47-111.

(2005) Vásquez, L: Aborto. Argumentos católicos a favor del derecho a decidir, Córdoba, Católicas por el Derecho a Decidir-Córdoba.

(2011) Villalba, Luis Héctor: "El aborto es un crimen que no se puede legitimar" en Agencia Informativa Católica Argentina (AICA) en: http://aica. org/index. php?module=displaystory\&story_id=25911\&format=html [20 de Enero de 2011]. 